\section{Vulnerability and non-adherence to antiretroviral therapy among HIV patients, Minas Gerais State, Brazil}

\author{
Vulnerabilidade e não-adesão à terapia \\ antiretroviral, Minas Gerais, Brasil
}

\begin{abstract}
The aim of the present study was to describe vulnerability profiles and to verify their association with non-adherence to antiretroviral therapy (ART) among 295 HIV-patients receiving their first prescription in two public-referral centers in Minas Gerais States, Brazil. The cumulative incidence of non-adherence was 36.9\%. Three pure vulnerability profiles (lower, medium and higher) were identified based on the Grade of Membership method (GoM). Pure type patients of the "higher vulnerability" profile had, when compared to the overall sample, an increased probability of being younger, not understanding the need of ART, having a personal reason to be HIV-tested, not disclosing their HIV status, having more than one (non-regular) sexual partner, reporting use of alcohol, tobacco and illicit drugs, and having sex among men. Non-adherence to ART was statistically associated $(p<0.001)$ with this profile. Also, the heterogeneity of the sample was found to be high, since over $40 \%$ were mixed type. The implications are that health staff should be trained to develop strategies for incorporating risk-reduction interventions, bearing in mind the three dimensions of vulnerability and the diversity of those patients initiating antiretroviral therapy.
\end{abstract}

HIV; Highly Active Antiretroviral Therapy; Vulnerability
Palmira de Fátima Bonolo 1

Carla Jorge Machado 2

Cibele Comini César 3

Maria das Graças Braga Ceccato 1

Mark Drew Crosland Guimarães 1

\section{Introduction}

Intervention programs aimed at high-risk populations in the area of HIV prevention have often been based on risk-taking assessments. Systematic screening of blood donations, voluntary testing of pregnant women, early diagnosis through counseling and testing of at risk populations (e.g., those with risky sexual behavior and drug use) and dissemination of adequate information about methods for preventing HIV transmission are among the strategies aimed at reducing the chances of acquiring or spreading HIV 1.

Several studies have focused on interactive and multidimensional bio-psychosocial factors that cause disparities and could undermine patient motivations to manage the AIDS disease and take preventive measures 2,3,4. Alves et al. 5 analyzed the risk perception among Brazilian women before getting a positive test result. None of them believed they could actually be infected; many had unprotected sex with their partners, and were prone to unwanted pregnancy and reinfection. Guerriero et al. ${ }^{6}$ pointed that feeling strong and immune to disease, engaging in impetuous risk behaviors, and believing that men needed sex more than women, were some aspects of masculinity associated with higher vulnerability to HIV among heterosexual men.

Mann \& Tarantola 7 defined vulnerability as susceptibility or factors related to individuals or groups that could increase or decrease the risk 
of an adverse event occurring. This concept has three dimensions: (1) individual vulnerability (physical and mental development, cognitive factors, behavioral and personal characteristics, skills, and social roles); (2) program-dependent vulnerability (provision of health and social services) and; (3) societal vulnerability (sexuality, gender, education and information, the supportive environment and livelihoods).

Indeed, vulnerability is a construct associated with governmental structures, gender relationships, and attitudes toward sexuality and poverty 7 . HIV/AIDS programs have to be expanded beyond the risk-reduction strategy and work toward societal factors. These programs strongly influence personal and programmatic vulnerability and need to be targeted towards reducing personal vulnerability to HIV. Also, viewing AIDS treatment from a perspective of vulnerability has several advantages and generates a challenge for public health. The interventions need to address political, economic, cultural and social issues that require long-term responses.

Improvements in the effectiveness of treatment may have an undesirable effect among people living with HIV/AIDS. The use of antiretroviral therapy (ART) may influence the type and extent of risk behavior for HIV transmission. It may be associated with either riskier or safer sexual behavior for reasons such as the recovery of health and sexual activities following a period of illness ${ }^{8}$. HIV infected individuals on therapy with undetectable viral load may feel confident that they could not infect others, thus reducing the likelihood of practicing safe sex 9 . In fact, a significant association was found between optimistic beliefs about ART and decreases in condom use over time 10 .

On the other hand, unprotected sexual activity could be a marker for non-adherence 11,12. Efforts made by health professionals to reduce HIV infection should aim at empowering patients to develop self-care management strategies in order to avoid risks and to cope with their therapy. A study of non-adherence to ART and unsafe sex with serodiscordant partners in Brazil, (which included in the analysis the participant's socio-demographic background, experiences and behaviors), showed that for heterosexual women, non-adherence and unsafe sex were positively correlated 12 . For heterosexual men, these behaviors were weakly correlated; finally, for men who had sex with men other factors were associated with non-adherence, such as duration since HIV diagnosis and life-time suicidal attempts. The authors concluded that behavior interventions should take into account this diversity 12 .
Crepaz et al. 13 showed that interventions significantly reduced self-reported unprotected sex and decreased the acquisition of sexually transmitted diseases among people living with HIV/AIDS. Providers should, therefore, consider integrating theory-based prevention within routine medical care and services, and addressing aspects of mental health and adherence to ART in addition to HIV risk behavior. Kerrigan et al. 14 found that the availability of ART was taken as a rationale for unsafe sex among minority participants (heterosexual women, heterosexual men, and men who had sex with men). The three groups showed fear or anxiety for behaviors such as disclosure and condom use. The authors concluded that health education on issues such as treatment optimism, disclosure, and condom use may not be sufficient for reaching people living with HIV/AIDS.

The present study considered non-adherence as the adverse health event. The objectives were to present a vulnerability construct and to identify its association with non-adherence to ART. The assumption was that vulnerability profiles depend on psycho-social dynamics of individual sexual relationships, ART-related beliefs, and the referred fear to disclosure. In order to build this vulnerability construct, a multivariate statistical method, Grade of Membership (GoM), was used.

\section{Methods}

\section{Subjects and recruitment}

The present analysis was part of a prospective study on adherence to ART carried out at two public AIDS-referral centers in the city of Belo Horizonte, Minas Gerais State, Brazil 15. Patients receiving their first antiretroviral (ARV) prescription from May 2001 through May 2002 were recruited and followed up to May 2003. The project was submitted and approved by the Ethical Research Committee of the Universidade Federal de Minas Gerais (ETIC 106/99). Participants were assessed soon after receiving their first ARV drugs from the pharmacies at each center (baseline interview), and in the $1^{\text {st }}, 4^{\text {th }}$, and 7 th months after initiating therapy (followup visits). Patients were included in this study if they had confirmed HIV infection and had never taken any ARV before, were 18 years old or older, and signed a written consent form. Sociodemographic and behavior characteristics were collected during baseline interview and non-adherence data from follow-up visits. 


\section{Grade of Membership analysis (GoM)}

GoM is a multivariate statistical technique suited to profiling vulnerability. It is a method of analyzing multidimensional categorical data, i.e., data consisting of several different measurements for each individual. Each of these measurements defines a dimension. It simultaneously estimates types of vulnerability profiles and estimates a grade of membership of each patient within each profile. The profiles can be described as the probability of the occurrence of the characteristics that are specific to individuals with full membership (or closer resemblance) 16 .

An important concept is that no one is required to be a member of any of these pure profile groups and, in this sense GoM is a "fuzzy" method 16. Any individual may be a partial member of two or more of the pure profile groups. In the present study, the GoM model estimated the degree to which each patient in the data set belonged to each of these pure profiles. Each patient was, then, represented by a set of grade of membership or scores, $g_{i k}$ where "i" is the individual and " $k$ " the pure type, which vary between zero (0) and one (1), and add up to one for each individual, specifying the state of that person. For example an individual for which a certain set of behavior characteristics is defined might have a grade of membership of 0.6 for one "extreme profile", 0.2 for the second, and 0.2 for the third, in a fuzzy set terminology. Conditionally on the information contained in the scores, the individual's responses to each measurement are independent 16 .

The concept discussed above can be expressed in terms of a mathematical model. Suppose there are "J" different behavior variables, and that a variable " $\mathrm{j}$ " has "l" levels (i.e., $\mathrm{L}_{\mathrm{j}}$ presents the number of different choices for the $j$ th variable). Variable "j" might represent condom use, which has $L_{j}=2$ different levels: regular or non-regular use for a particular person. Assuming " $k$ " extreme profiles and patients indexed as "i", the parameters of the model are: $g_{i k}$ represents the grade of membership of patient "i" in the extreme profile " $k$ " and $\lambda_{\mathrm{kjl}}$ represents the probability that behavior level "l" of variable $j$ will be chosen by someone with full membership in profile " $\mathrm{k}$ " 16 . To summarize, GoM does not only create groups of similar entities, but also takes into account individual differences. Therefore, GoM is suited for modeling profiles where heterogeneity exists.

\section{Vulnerability profile structure (internal} variables)

In the present analysis, vulnerability to HIV was assessed through the socio-demographic characteristics, beliefs, attitudes, and practices of the patients. The variables selected to define the profile structure, i.e., the internal variables, were: age, gender, race, individual income, understanding the need for ART, reason for having been HIV tested, communicating the HIV status to someone, living with someone who was also HIV tested, sexual partners and irregular (not using all the time) condom use, use of alcohol, illicit drugs, injecting drugs and tobacco. These characteristics were assessed during baseline interviews and altogether they built the vulnerability construct to be evaluated. GoM-derived pure vulnerability profiles were then obtained from internal variables (21 variables).

In order to define the characteristics of each profile as akin to vulnerability, the following category of variables were chosen as representing a positive relation to vulnerability: age (less than 35 years old), gender (female), race (afro-descendent), individual income (less than US\$80), understanding the need for ART (no), reason to have been HIV tested (personal or both), communicated their HIV status to someone close (no), sexual partner(s) who had also been tested for HIV (positive), sexual partners in lifetime/last month (more than one or non-regular), men who had sex with men (yes), condom use in lifetime/ last month (irregular), illicit drug use in lifetime/ last month (yes), ever used injecting drug (yes), alcohol use in last month (yes), and, finally, tobacco use (yes). The total number of risk categories was 22 .

\section{Adverse health effects (conditional or external variable)}

The first occurrence of non-adherence to ART was considered the external variable for which a profile vector was computed, with this vector being conditional on the defined vulnerability structure. This was defined as the intake of less than $95 \%$ of the prescribed number of doses and measured by self-reported standard interviews related to the number of prescribed doses of each ARV taken during the three days prior to each follow-up visit. Although non-adherence does not form part of the definition of the profile structure, its association with those profiles provides valuable information about the correlation with a group of characteristics that defines each pure profile. 


\section{Statistical analysis}

Cumulative and person-time incidence of nonadherence was estimated. For both, the numerator was the number of patients taking less than 95\% of the prescribed number of ARV doses during the three days prior to the interview. The denominator was the number of patients who returned for at least one follow-up visit for the former and the sum of the times contributed by each individual for the latter. Time was defined as the number of days between date of the baseline interview and date of the interview indicating first non-adherence episode or date of last interview for those considered to be adherent.

GoM analysis was applied to the data set, testing for the optimal number of pure types. The significance of adding the $K+1$ profile was tested as an independent increment in the fit of the model adjusting for the larger number of degrees of freedom in the larger model. Akaike information criterion (AIC) was calculated and the lowest value of the AIC designates the best model, namely the model with the best fit and least bias 17 . The profiles were described for the quotient of the $\lambda_{\mathrm{kjl}}$ values (estimates of probabilities) divided by the marginal (observed) frequencies. If the quotient $\mathrm{E} / \mathrm{O}$ were smaller than 1.10, the first value (numerator) was considered as having less discrimination power than the second one (denominator). This chosen value was lower than that used by Sawyer et al. 18, but it was applied in order to ascertain better the heterogeneity of the sample, allowing for the inclusion of more categories in describing each profile.

GoM can assume values in the interval $(0,1)$. As a rule, if an individual had $g_{i k}$ equal to 1 , he/she was defined as pure or extreme type of profile " $k$ ". The assumption in the present study was that if $g_{i k}$ was at least 0.75 for an individual, he/she was considered as admissible to a pure type " $k$ ". If an individual had a $g_{i k}$ between 0.50 (inclusive) and 0.75 (exclusive) he was considered to have a membership score of a mixed type. The three pure or extreme profile types were classified based on an increasing risk of non-adherence in: P1 or medium vulnerability; P2 or lower vulnerability; and P3 or higher vulnerability. In order to do this classification, first it was assessed whether the quotient $\mathrm{E} / \mathrm{O}$ was higher than 1.10 for each category of each one of the 21 variables. Then, the risk categories for which the E/O was above 1.10 were added. Next, the profiles were ordered according to the level of vulnerability (lower, medium or higher). The profile that had the higher number of risky categories was considered to be of "higher vulnerability". Following the same reasoning, the "medium vulnerability" profile and the "lower vulnerability" profile were named.

The magnitude of the association between the profile types and the first non-adherence episode were estimated by the relative hazard $(\mathrm{RH})$ with 95\% confidence interval (95\%CI), obtained from Cox's proportional hazard model 19. The level of significance considered for this analysis was 0.05 .

\section{Results}

From a total of 306 subjects who returned for at least one follow-up visit, 295 (96.4\%) were eligible for inclusion in the analysis. Overall cumulative incidence of non-adherence was $36.9 \%$ and person-time incidence was $0.21 / 100$ person-days. Descriptive characteristics presented in Table 1 indicate that most participants were between 30 and 39 years old, male, afro-descendent and had low individual income. The majority understood the need of ART and had communicated their HIV status to someone close to them. Lifetime irregular condom use (not using condoms in all sexual practices) was reported by $94.5 \%$ patients. It should be noticed that, among those reporting any sexual contact, in the past month, $34.6 \%$ continued to practice unsafe sex.

Three model-based profiles best represented the vulnerability among HIV-patients initiating antiretroviral therapy. They are labeled P1, P2, P3 in the order of increasing vulnerability. Each profile was defined by the probabilities of a response for each variable, akin to the frequencies found in the sample as a whole. Table 2 shows the distribution of sample frequencies of internal variables (observed values), external variable (non-adherence), and lambda coefficients $\left(\lambda_{\mathrm{kjl}}\right)$ of internal variables for each pure or extreme type (estimated values). It also presents the quotient of the $\lambda_{\mathrm{kjl}}$ (estimated probability) values divided by the marginal (observed) frequency (E/O quotient).

As indicated in Table 2, the pure type individuals of the extreme profile 1 (P1) had a higher probability (P1) of being older, female patients, white, reporting a personal reason or a medical reason, not communicating their HIV status, not living with someone who has tested for HIV, having only one sexual partner in a lifetime, having no sexual partner in the previous month, not having sex among men, never having ever used illicit drugs, nor alcohol or tobacco. Among these characteristics, only being a female, having a personal and a medical indication to be tested and not communicating their HIV status were risky categories (3 categories). 
Selected descriptive characteristics among 295 participants. Belo Horizonte, Minas Gerais State, Brazil, 2001-2003.

\begin{tabular}{|c|c|c|}
\hline Characteristics * & $\mathrm{n} * *$ & $\%$ \\
\hline Age (30-59 years old) & 233 & 86.6 \\
\hline Gender (male) & 192 & 65.8 \\
\hline Race (afro-descendent) & 211 & 72.3 \\
\hline Individual monthly income ( $\leq$ US\$ 80.00) *** & 168 & 57.5 \\
\hline Understanding the need for antiretroviral therapy (yes) & 270 & 92.5 \\
\hline Reason for being tested for HIV (medical indication) & 192 & 65.8 \\
\hline Communicated their HIV status to a someone close to them (yes) & 252 & 86.3 \\
\hline Lived with someone who had also been tested for HIV (yes) & 131 & 44.9 \\
\hline Sexual partners who had also been tested for HIV (positive) & 107 & 36.6 \\
\hline Sexual partners (lifetime) (more than one) & 251 & 86.0 \\
\hline Sexual partners in month prior to the baseline interview (one) $* \star \star$ & 119 & 40.8 \\
\hline Sexual partners lifetime (fixed) & 220 & 75.3 \\
\hline Sexual partners last month (fixed) \# & 113 & 38.7 \\
\hline Men who had sex with men (yes) & 89 & 30.5 \\
\hline Lifetime condom use (irregular) & 276 & 94.5 \\
\hline Condom use in month prior to the baseline interview (irregular) & 45 & 34.6 \\
\hline Ever used any illicit drug (yes) & 81 & 27.7 \\
\hline Illicit drug use in month prior to the baseline interview (yes) & 25 & 8.6 \\
\hline Ever used injecting drug (yes) & 17 & 5.8 \\
\hline Alcohol use in month prior to the baseline interview (yes) & 109 & 37.3 \\
\hline Tobacco (current use) & 99 & 33.9 \\
\hline
\end{tabular}

* Variable categories are presented in parenthesis;

** Total for each variable differs due to missing values;

*** Equivalent to the monthly minimum wage in Brazil;

\# Among 130 who had sexual partners in the month prior to the baseline interview.

Pure types of the extreme profile 2 (P2) had a higher probability of being younger, female, having a lower income, having a medical reason to have been HIV tested, having communicated their HIV status, living with someone who has tested for HIV, having a sexual partner who tested positive for HIV, having only one sexual partner in their lifetime and in the previous month, having a fixed sexual partner in the last month, not having sex among men, having used a condom in the previous month (regularly or irregularly), having never used illicit drugs, having used alcohol, but not having used tobacco. Among these characteristics, being younger, female, having a lower income, living with someone who has tested for HIV, having a sexual partner who tested positive for HIV, having irregular condom use in the previous month and having used alcohol in the previous month were the risk categories that were in the description of the profile (7 categories).

Pure types of extreme profile 3 (P3) had a higher probability of being younger, male, not understanding the need for ART, having a per- sonal reason for being HIV tested, having not communicated their HIV status to someone close to them, living alone and without a sexual partner, having more than one and no fixed sexual partner in their lifetime, having more than one and most of them casual relationships (nonregular partner) in the previous month, or having not reported sexual activity in the previous month. There was also a higher probability of sex among men, irregular use of condom in their lifetime, use of illicit drugs, injecting drugs, alcohol and tobacco. Among these characteristics, being younger, not understanding the need of ART, having a personal reason for testing for HIV, having not communicated their HIV status, having more than one sexual partner in a lifetime and in the previous month, having a non-fixed partner in their lifetime and in the previous month, having sex among men, having used any illicit drugs (in the previous month and over their lifetime), alcohol and tobacco were the risk categories that contributed to the description of the profile (14 categories). 
Marginal frequencies, estimates of probabilities $\left(\lambda_{\mathrm{kj}}\right)$ * of internal and external variables for each pure profile $(\mathrm{P})$ and quotient E/O **. Belo Horizonte, Minas Gerais State, Brazil, 2001-2003.

\begin{tabular}{|c|c|c|c|c|c|c|c|c|}
\hline \multirow[t]{2}{*}{ Variables } & \multicolumn{2}{|c|}{ Observed frequency $* \star \star$} & \multicolumn{3}{|c|}{ 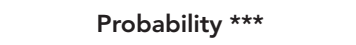 } & \multicolumn{3}{|c|}{$\mathrm{E} / \mathrm{O} \#$} \\
\hline & $\mathbf{N}$ & $\%$ & $\lambda_{\mathrm{kj} 1}$ & $\lambda_{\mathrm{kj} 2}$ & $\lambda_{\mathrm{kj} 3}$ & P1 & P2 & P3 \\
\hline \multicolumn{9}{|l|}{ Age (years) } \\
\hline $60-72$ & 6 & 0.02 & 0.05 & 0.00 & 0.00 & 2.50 & 0.00 & 0.00 \\
\hline $30-59$ & 256 & 0.87 & 0.90 & 0.85 & 0.83 & 1.03 & 0.98 & 0.95 \\
\hline $18-29$ & 33 & 0.11 & 0.05 & 0.15 & 0.17 & 0.45 & 1.36 & 1.54 \\
\hline \multicolumn{9}{|l|}{ Gender } \\
\hline Male & 195 & 0.66 & 0.47 & 0.57 & 1.00 & 0.71 & 0.86 & 1.51 \\
\hline Female & 100 & 0.34 & 0.53 & 0.43 & 0.00 & 1.56 & 1.26 & 0.00 \\
\hline \multicolumn{9}{|l|}{ Race } \\
\hline White & 74 & 0.25 & 0.32 & 0.20 & 0.21 & 1.28 & 0.80 & 0.84 \\
\hline Afro-descendent & 212 & 0.72 & 0.65 & 0.78 & 0.76 & 0.90 & 1.08 & 1.05 \\
\hline \multicolumn{9}{|l|}{ Individual monthly income } \\
\hline$>$ US\$ 80.00 & 127 & 0.43 & 0.46 & 0.35 & 0.47 & 1.07 & 0.81 & 1.09 \\
\hline$\leq$ US\$ 80.00 & 168 & 0.57 & 0.54 & 0.65 & 0.53 & 0.95 & 1.14 & 0.93 \\
\hline \multicolumn{9}{|c|}{ Understanding the need for antiretroviral therapy } \\
\hline Yes & 273 & 0.93 & 0.93 & 0.96 & 0.88 & 1.00 & 1.03 & 0.95 \\
\hline No & 21 & 0.07 & 0.07 & 0.04 & 0.12 & 1.00 & 0.57 & 1.71 \\
\hline \multicolumn{9}{|l|}{ Reason for testing for HIV } \\
\hline Personal reasons & 84 & 0.29 & 0.20 & 0.27 & 0.44 & 0.69 & 0.93 & 1.52 \\
\hline On doctor's recommendation & 193 & 0.66 & 0.66 & 0.73 & 0.56 & 1.00 & 1.11 & 0.85 \\
\hline Both & 17 & 0.06 & 0.14 & 0.00 & 0.00 & 2.33 & 0.00 & 0.00 \\
\hline \multicolumn{9}{|l|}{ Communicated their HIV status } \\
\hline Yes & 255 & 0.86 & 0.78 & 1.00 & 0.81 & 0.90 & 1.16 & 0.94 \\
\hline No & 40 & 0.14 & 0.22 & 0.00 & 0.19 & 1.57 & 0.00 & 1.36 \\
\hline \multicolumn{9}{|c|}{ Lived with someone who has tested for HIV } \\
\hline Yes & 132 & 0.45 & 0.38 & 0.89 & 0.00 & 0.84 & 1.98 & 0.00 \\
\hline No & 99 & 0.34 & 0.51 & 0.11 & 0.36 & 1.50 & 0.32 & 1.06 \\
\hline Live alone & 56 & 0.19 & 0.11 & 0.00 & 0.53 & 0.58 & 0.00 & 2.79 \\
\hline \multicolumn{9}{|c|}{ Sexual partners who had also been tested HIV } \\
\hline Positive & 109 & 0.37 & 0.32 & 0.72 & 0.00 & 0.86 & 1.94 & 0.00 \\
\hline Negative & 44 & 0.16 & 0.16 & 0.19 & 0.08 & 1.00 & 1.19 & 0.50 \\
\hline Without partner & 122 & 0.41 & 0.45 & 0.00 & 0.87 & 1.10 & 0.00 & 2.12 \\
\hline \multicolumn{9}{|l|}{ Sexual partners (lifetime) } \\
\hline One & 40 & 0.14 & 0.19 & 0.17 & 0.00 & 1.36 & 1.21 & 0.00 \\
\hline More than one & 254 & 0.86 & 0.80 & 0.83 & 1.00 & 0.93 & 0.96 & 1.16 \\
\hline \multicolumn{9}{|l|}{ Sexual partners (last month) } \\
\hline One & 120 & 0.41 & 0.00 & 1.00 & 0.00 & 0.00 & 2.44 & 0.00 \\
\hline More than one & 10 & 0.03 & 0.00 & 0.00 & 0.13 & 0.00 & 0.00 & 4.33 \\
\hline Without partner & 165 & 0.56 & 1.00 & 0.00 & 0.87 & 1.78 & 0.00 & 1.55 \\
\hline \multicolumn{9}{|l|}{ Sexual partners (lifetime) } \\
\hline Fixed & 73 & 0.25 & 0.00 & 0.03 & 0.14 & 0.00 & 0.12 & 0.56 \\
\hline Non-fixed & 221 & 0.75 & 0.97 & 0.97 & 0.86 & 0.77 & 0.77 & 1.15 \\
\hline \multicolumn{9}{|l|}{ Sexual partners (last month) } \\
\hline Fixed & 114 & 0.39 & 0.00 & 1.00 & 0.00 & 0.00 & 2.56 & 0.00 \\
\hline Non-fixed & 16 & 0.05 & 0.00 & 0.00 & 0.22 & 0.00 & 0.00 & 4.40 \\
\hline \multicolumn{9}{|l|}{ Sex among men } \\
\hline Yes & 91 & 0.31 & 0.00 & 0.00 & 1.00 & 0.00 & 0.00 & 3.22 \\
\hline No & 203 & 0.69 & 1.00 & 1.00 & 0.00 & 1.44 & 1.44 & 0.00 \\
\hline \multicolumn{9}{|l|}{ Lifetime condom use } \\
\hline Regular & 13 & 0.04 & 0.00 & 0.00 & 0.11 & 0.00 & 0.00 & 2.75 \\
\hline Irregular & 279 & 0.95 & 1.00 & 1.00 & 0.89 & 1.05 & 1.05 & 0.94 \\
\hline
\end{tabular}

(continues) 


\begin{tabular}{|c|c|c|c|c|c|c|c|c|}
\hline \multirow[t]{2}{*}{ Variables } & \multicolumn{2}{|c|}{ Observed frequency *** } & \multicolumn{3}{|c|}{ 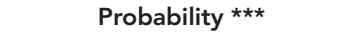 } & \multicolumn{3}{|c|}{$\mathrm{E} / \mathrm{O} \#$} \\
\hline & $\mathbf{N}$ & $\%$ & $\lambda_{\mathrm{kj} 1}$ & $\lambda_{\mathrm{kj} 2}$ & $\lambda_{\mathrm{kj} 3}$ & P1 & P2 & P3 \\
\hline \multicolumn{9}{|c|}{ Condom use in previous month } \\
\hline Regular & 82 & 0.28 & 0.00 & 0.62 & 0.00 & 0.00 & 2.21 & 0.00 \\
\hline Irregular & 46 & 0.16 & 0.00 & 0.38 & 0.00 & 0.00 & 2.37 & 0.00 \\
\hline Without partner & 167 & 0.57 & 1.00 & 0.00 & 1.00 & 1.75 & 0.00 & 1.75 \\
\hline \multicolumn{9}{|c|}{ Ever used any illicit drug } \\
\hline Yes & 83 & 0.28 & 0.00 & 0.08 & 1.00 & 0.00 & 0.28 & 3.57 \\
\hline No & 212 & 0.72 & 1.00 & 0.92 & 0.00 & 1.39 & 1.28 & 0.00 \\
\hline \multicolumn{9}{|c|}{ Illicit drug use (last month) } \\
\hline Yes & 25 & 0.09 & 0.00 & 0.00 & 0.36 & 0.00 & 0.00 & 4.00 \\
\hline No & 270 & 0.91 & 1.00 & 1.00 & 0.64 & 1.09 & 1.09 & 0.70 \\
\hline \multicolumn{9}{|c|}{ Injecting drug use (lifetime) } \\
\hline Yes & 17 & 0.06 & 0.00 & 0.00 & 0.23 & 0.00 & 0.00 & 3.83 \\
\hline No & 278 & 0.94 & 1.00 & 1.00 & 0.76 & 1.06 & 1.06 & 0.81 \\
\hline \multicolumn{9}{|c|}{ Alcohol use (last month) } \\
\hline Yes & 111 & 0.37 & 0.00 & 0.46 & 0.84 & 0.00 & 1.24 & 2.27 \\
\hline No & 184 & 0.63 & 1.00 & 0.54 & 0.16 & 1.59 & 0.86 & 0.25 \\
\hline \multicolumn{9}{|c|}{ Tobacco (current use) } \\
\hline Yes & 101 & 0.34 & 0.00 & 0.26 & 1.00 & 0.00 & 0.76 & 2.94 \\
\hline No & 194 & 0.66 & 1.00 & 0.74 & 0.00 & 1.51 & 1.12 & 0.00 \\
\hline \multicolumn{9}{|l|}{ Adherence } \\
\hline Adherent & 193 & 0.63 & 0.72 & 0.55 & 0.59 & 1.14 & 0.87 & 0.94 \\
\hline Non-adherent & 102 & 0.37 & 0.27 & 0.45 & 0.41 & 0.73 & 1.22 & 1.11 \\
\hline
\end{tabular}

* $\lambda_{\mathrm{kj}}$ : probability that behavior level "I" of variable " $\mathrm{j}$ " will be chosen by someone with full membership in profile "k";

** Quotient between estimated $(\lambda)$ probability and marginal (observed) frequency;

$\star \star \star$ Sum of categories differs from one as a result of missing values;

\# Bold type indicates quotients reaching $\geq 1.10$.

Given the results, pure profiles P1, P2 and P3 were defined as lower, medium and higher vulnerability, respectively. This classification was based on the number of risk categories. P1, P2 and $\mathrm{P} 3$ had 3, 7 and 14 risk categories respectively with E/O above 1.10. In general, P3 (higher vulnerability) was the only one with a higher probability of patients using illicit drugs, and tobacco and reporting sex among men and also with people who think that they did not need ART. In relation to the external variable, pure types of P2 and P3 had higher probability of being non-adherent patients as compared to P1 (Table 2).

Table 3 shows the distribution of individual coefficients $\left(\mathrm{g}_{\mathrm{ik}}\right.$ ) for the 295 subjects. Most patients (57.9\%) were classified as pure or admissible profiles. Pure and admissible profile percentages were predominant for the medium and lower vulnerability, scoring $69.1 \%$ (76/110), $66.1 \%$ (80/121) respectively, and the mixed type $(74.6 \%)$ for the higher vulnerability profile (44/59).

Finally, the results of the association between the three pure profile types and the first non-adherence episode (Table 4 ) indicated that non-adherence was statistically associated ( $\mathrm{p}<$ 0.001 ) with P3, denominated higher vulnerability profile.

\section{Discussion}

In the present study GoM analysis was used to summarize and characterize the heterogeneous vulnerability profiles. This approach avoided multiple comparisons between each pair of variables and was able to assign a level of membership in the vulnerable groups for each individual. The method applied here took into consideration the heterogeneity of the study sub-samples in profiling vulnerability. Since vulnerability is a multidimensional construct, taking into account the diversity among patients was important. Another advantage was that surrogate measures of vulnerability, such as subjective scores, were not used.

Overall, a high incidence of non-adherence (36.9\%) soon after the beginning of the treatment was found for the study patients. Considering 
Distribution of individual Grade of Membership (GoM) scores $\left(g_{i k}\right)$ * for each pure type $(N=295)$. Belo Horizonte, Minas Gerais State, Brazil, 2001-2003.

\begin{tabular}{|c|c|c|}
\hline Profile & Frequency & Percentage \\
\hline \multicolumn{3}{|l|}{ P1: lower vulnerability } \\
\hline Pure (or extreme) type ** & 44 & 14.9 \\
\hline Admissible type & 36 & 12.2 \\
\hline Mixed type & 41 & 13.9 \\
\hline Total & 121 & 41.0 \\
\hline \multicolumn{3}{|l|}{ P2: medium vulnerability } \\
\hline Pure (or extreme) type ** & 47 & 16.0 \\
\hline Admissible type & 29 & 9.8 \\
\hline Mixed type & 34 & 11.5 \\
\hline Total & 110 & 37.3 \\
\hline \multicolumn{3}{|l|}{ P3: higher vulnerability } \\
\hline 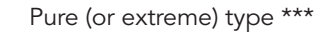 & 4 & 1.3 \\
\hline Admissible type & 11 & 3.7 \\
\hline Mixed type & 44 & 15.0 \\
\hline Total & 59 & 20.0 \\
\hline Amorphous profile ${ }^{\star \star \star}$ & 5 & 1.7 \\
\hline Total & 295 & 100.0 \\
\hline
\end{tabular}

* $g_{i k}$ : obtained from an individual grade of membership score;

** Pure type $\left(g_{i k}=1.00\right)$, admissible type $\left(g_{i k} \geq 0.75\right)$ and mixed type $\left(0.50 \leq g_{i k}<0.75\right)$;

*** Amorphous type $\left(g_{i k} \leq 0.50\right)$

Table 4

Analysis of the association between the first episode of antiretroviral non-adherence and the pure profiles. Belo Horizonte, Minas Gerais State, Brazil ( $\mathrm{N}=295)$, 2001-2003.

\begin{tabular}{|c|c|c|c|c|c|c|}
\hline \multirow[t]{2}{*}{ Characteristic } & \multirow[t]{2}{*}{ Total } & \multicolumn{2}{|c|}{ Non-adherence } & \multirow[t]{2}{*}{ Relative hazard * } & \multirow[t]{2}{*}{$95 \% \mathrm{Cl}$} & \multirow[t]{2}{*}{$p$ value } \\
\hline & & $\mathrm{n}$ & $\%$ & & & \\
\hline \multicolumn{7}{|l|}{ Profiles } \\
\hline P3: higher vulnerability & 59 & 42 & 71.2 & 2.85 & $1.76-4.63$ & $<0.001$ \\
\hline P2: medium vulnerability & 110 & 20 & 18.2 & 0.69 & $0.38-1.24$ & 0.216 \\
\hline P1: lower vulnerability & 121 & 27 & 22.3 & 1.00 & - & - \\
\hline
\end{tabular}

* Obtained from Cox proportional hazard model.

that the higher vulnerability profile was strongly associated with non-adherence to ART, there is a need to take action, as soon as treatment begins, in order to improve and maintain adherence in the long run, given the complexity of AIDS treatment. Issues such as drug use could be addressed by providing supportive services while others might respond to other kinds of interventions to increase self-motivation and bring a positive change in patients' lives.
Based on the vulnerability profiles found in the present study, health professionals might focus on individual vulnerability such as younger patients, those who think that they did not need ART, and those who live alone in order to offer them on-going medical counseling and help them to look for alternative support groups, e.g. non-governmental organizations.

Regarding each pure profile, it should be noted that not having communicated their HIV sta- 
tus to someone close to them was one characteristic found among the lower and medium vulnerability profiles. Those patients did not experience the benefits of disclosure, probably because they might fear or experience social and personal negative consequences originating from discrimination against AIDS. Another possibility is that they lived alone 20 . In fact, the heterogeneity of the vulnerability profiles, as shown by the fact that more than $40 \%$ of the sample could not be characterized within a single profile, should be taken into consideration to improve training for health professionals. They might affect patients in positive ways by communicating preventive messages, discussing sexual and drug-use behaviors, reinforcing changes to safer practices, referring patients for support services or organizations and also facilitating partner counseling 21 . Health staff should be trained to develop strategies for incorporating risk-reduction interventions, considering the three dimensions of vulnerability of those patients initiating ART addressed in this analysis.

Studies that assess the vulnerability of HIVinfected individuals initiating ART in Brazil are scarce. Based on the findings of the present study there is a diversity of vulnerability types of individuals. Therefore, there is a need for an environment with comprehensive health services to account for the diversity of people living with HIV/AIDS. Programs such as those found in
Brazil that offer universal access to ART need to broaden their clinical care in order to correlate treatment with sexual and reproductive healthrelated rights. Patients who experience non-adherence to ART and engage in unsafe sex need practical and social support. Not recognizing the diversity among people living with HIV/AIDS may involuntarily create an environment with stigma even among health professionals in the HIV reference centers 12,22 .

Strategies to improve adherence to antiretroviral therapy and effective risk-reduction go hand in hand. Safe counseling messages must be an ongoing part of clinical care, and should be provided as early and often as possible. From a programmatic standpoint, individuals can certainly gain benefits from access to integrated care with an emphasis on prevention. Programmatic vulnerability has elements to reduce personal vulnerability through working information and education, health and social services, and nondiscrimination towards HIV-infected people 7.

The realities of women and men strongly influence their vulnerability to HIV/AIDS. To reach accessibility and health service quality, decreasing, therefore, the risk of non-adherence to ART, there is a need to expand people's capacity to exert control over their health in their complex social-cultural contexts. Understanding vulnerability and heterogeneity among individuals is certainly a first step. 


\section{Resumo}

Este estudo teve como objetivos descrever os perfis de vulnerabilidade e verificar suas associações com a não-adesão à terapia anti-retroviral (TARV) entre os 295 pacientes com HIV que recebiam suas primeiras prescrições em dois serviços públicos de referência de Minas Gerais, Brasil. A incidência cumulativa de não-adesão foi 36,9\%. Foram identificados três perfis puros de vulnerabilidade (baixa, média e alta) baseados no método Grade of Membership (GoM). Os tipos puros de pacientes do perfil de "alta vulnerabilidade" tinham, comparados aos outros, probabilidade maior de serem jovens, de não perceberem a necessidade da $T A R V$, de terem uma razão pessoal para realização do teste HIV, de não terem revelado seu status HIV, de terem mais de um (não fixo) parceiro sexual, de relatarem uso de álcool, tabaco e drogas ilícitas e sexo entre homens. Não-adesão à TARV foi associada significativamente a esse perfil $(p<0,001)$. A heterogeneidade da amostra foi alta, pois mais de $40 \%$ dos pacientes eram tipos mistos. Conclui-se que os profissionais de saúde devem ser treinados para desenvolverem estratégias e intervenções de redução de risco, considerando as três dimensões da vulnerabilidade e a diversidade desses pacientes iniciando a TARV.

HIV; Terapia Anti-Retroviral de Alta Atividade; Vulnerabilidade

\section{References}

1. Salomon JA, Hogan DR, Stover J, Stanecki KA, Walker N, Ghys PD, et al. Integrating HIV prevention and treatment: from slogans to impact. PLoS Med 2005; 2:e16.

2. Delor F, Hubert M. Revisiting the concept of vulnerability. Soc Sci Med 2000; 50:1557-70.

3. Lansky A, Nakashima AK, Jones JL. Risk behaviors related to heterosexual transmission from HIV-infected persons. Sex Transm Dis 2000; 27:483-9.

4. Ayres JRCM, França Júnior I, Calazans GJ, Saletti Filho HC. O conceito de vulnerabilidade e as práticas de saúde: novas perspectivas e desafios. In: Czeresnia D, Freitas CM, organizadores. Promoção da saúde: conceitos, reflexões, tendências. Rio de Janeiro: Editora Fiocruz; 2003. p. 117-40.

5. Alves RN, Kovacs MJ, Stall R, Paiva V. Fatores psicossociais e a infecção por HIV em mulheres, Maringá, PR. Rev Saúde Pública 2002; 36:32-9.

6. Guerriero I, Ayres JRCM, Hearst N. Masculinidade e vulnerabilidade ao HIV de homens heterossexuais, São Paulo, SP. Rev Saúde Pública 2002; 36: 50-60.

\section{Contributors}

P. F. Bonolo, M. G. B. Ceccato and M. D. C. Guimarães were responsible for the study design, the data analysis and interpretation, writing up and revising the text and approving the final version of the article. C. C. César and C. J. Machado took part in the data analysis and interpretation.

\section{Acknowledgments}

This study received support as part of the ATAR Project, sponsored by the Pan-American Health Organization and the National AIDS Program of the Brazilian Ministry of Health (PN-DST/AIDS Brasil - UNESCO 914/BRA/3014) and was developed by the Research Group on Epidemiology and Health Services Evaluation (GPEAS) at the Federal University of Minas Gerais
7. Mann J, Tarantola D, editors. AIDS in the world II: global dimensions, social roots, and responses. New York: Oxford University Press; 1996.

8. Duckers NHTM, Goudsmit J, De Wit JBF, Prins M, Weverling GJ, Coutinho RA. Sexual risk behavior relates to the virological and immunological improvements during highly active antiretroviral therapy in HIV-1 infection. AIDS 2001; 15:369-78.

9. Crepaz N, Hart TA, Marks G. Highly active antiretroviral therapy and sexual risk behavior: a metaanalytic review. JAMA 2004; 292:224-36.

10. Huebner DM, Rebchook GM, Kegeles SM. A longitudinal study of the association between treatment optimism and sexual risk behavior in young adult gay and bisexual men. J Acquir Immune Defic Syndr 2004; 37:1514-9.

11. Wilson TE, Barrón Y, Cohen M, Richardson J, Greenblatt R, Sacks HS, et al. Adherence to antiretroviral therapy and its association with sexual behavior in a national sample of women with human immunodeficiency virus. Clin Infect Dis 2002; 34:529-34. 
12. Peretti Watel P, Spire B, Schiltz MA, Bouhnik AD, Heard I, Lert F, et al. Vulnerability, unsafe sex and non-adherence to HAART: evidence from a large sample of French HIV/AIDS outpatients. Soc Sci Med 2006; 62:2420-33.

13. Crepaz N, Lyles CM, Wolitski RJ, Passin WF, Rama $\mathrm{SM}$, Herbst JH, et al. Do prevention interventions reduce HIV risk behaviors among people living with HIV? A meta-analytic review of controlled trials. AIDS 2006; 20:143-57.

14. Kerrigan D, Bastos FI, Malta M, Carneiro-da-Cunha C, Pilotto JH, Steffanie AS. The search for social validation and the sexual behavior of people living with HIV in Rio de Janeiro, Brazil: understanding the role of treatment optimism in context. Soc Sci Med 2006; 62:2386-96.

15. Bonolo PF, César CC, Acúrcio FA, Ceccato MGB, Pádua CAM, Álvares J, et al. Non-adherence among patients initiating antiretroviral therapy: a challenge for health professionals in Brazil. AIDS 2005; 19 Suppl 4:S5-13.

16. Manton KG, Woodbury MA, Tolley HD. Statistical applications using fuzzy sets. New York: John Wiley and Sons; 1994.
17. Akaike H. Information theory and an extension of the maximum likelihood principle. In: Proceedings of the $2^{\text {nd }}$ International Symposium on Information Theory. Budapest: Akademiai Kiado; 1973. p. 267-81.

18. Sawyer DO, Leite IC, Alexandrino R. Perfis de utilização de serviços de saúde no Brasil. Ciênc Saúde Coletiva 2002; 7:757-76.

19. Cox DR, Oakes D. Analysis of survival data. New York: Chapman and Hall; 1984

20. Chandra PS, Deepthivarma S, Jairam KR, Thomas T. Relationship of psychological morbidity and quality of life to illness-related disclosure among HIV-infected persons. J Psychosom Res 2003; 54:199-203.

21. Buchalla CM, Paiva V. Da compreensão da vulnerabilidade social ao enfoque multidisciplinar. Rev Saúde Pública 2002; 36:117-9.

22. Lusti-Narasimhan M, Cottingham J, Beber M. Ensuring the sexual and reproductive health of people living with HIV: policies, programmes and health services. Reprod Health Matters 2007; 15:1-3.

Submitted on $13 / \mathrm{Feb} / 2007$

Final version resubmitted on 27/Aug/2007

Approved on 31/Jan/2008 